\title{
The energy transition patterns of low-income households in South Africa: An evaluation of energy programme and policy
}

\author{
Sylvia Israel-Akinbo ${ }^{*}$, Jen Snowball, Gavin Fraser \\ Faculty of Commerce, Rhodes University, Grahamstown, 6139, South Africa
}

\begin{abstract}
The transition to modern energy carriers like electricity is an important way to achieve to eradicate energy poverty. This study investigated energy transition patterns and trends in low-income South African households. The marginal effects of the different determinants on the probability of choosing a specific energy carrier were computed and the influence of some endogenous characteristics in transitioning to modern energy carriers was explored. It was found that energy ladder behaviour exists for cooking while energy stacking was most likely for space heating and the pattern for lighting tended towards energy stacking. Dwelling type, household size and geographical location were among the key determinants of the energy transition pattern. Policies to reduce energy poverty need a multi-pronged approach and not only a focus on electricity access.
\end{abstract}

\begin{abstract}
Keywords: energy ladder; energy stacking; energy poverty; electricity
\end{abstract}




\section{Introduction}

Energy choices have a major impact on the energy system of a country and its economic development (Joyeux and Ripple, 2007; Lay et al., 2013). If a household relies mainly on traditional fuels for cooking, space heating or lighting, economic activities may be hindered (Lay et al., 2013; Liu et al., 2013; Van der Kroon et al., 2013). Shifting to modern energy carriers is associated with welfare improvement and is an important developmental goal to achieve, in order to eradicate energy poverty (Kowsari and Zerriffi, 2011; Liu et al., 2013). Provision of electricity in developing countries is generally recognised as a necessary foundation to eradicate energy poverty.

The South African government, in addressing the electricity imbalance in the residential sector, introduced several national programmes to widen access to electricity (Department of Energy [DoE], 2013), including the National Electrification Programme and the Integrated National Electrification Programme. The main objective of these programmes was to connect to the grid rural and urban low-income houses deprived of access to electricity during the apartheid period. The programme expected that the residents of the electrified houses would switch to electricity as the main energy source for their household needs. To address affordability problems related to electricity, the Department of Minerals and Energy (DME) in 2003 launched the Free Basic Electricity (FBE) programme. This provides $50 \mathrm{kWh}$ of electricity per month free of charge to poor households connected to the national electricity grid (DME 2003; Inglesi-Lotz, 2010; Ruiters, 2009).

Energy transition has been conceptualised in the form of the 'energy ladder' or 'energy stacking' models (Kowsari and Zerriffi. 2011; Lee et al., 2015; Van der Kroon et al., 2013). The energy ladder model aligns with the economic theory of the consumer and describes a linear transition of household energy choices from a traditional energy carrier to a transitional one and then to a modern one as income improves (Hosier and Dowd, 1987; Lee et al., 2015; Van der Kroon et al., 2013).

The energy stacking or multiple fuel use model, on the other hand, was developed based on findings that households choose to use a combination of energy carriers on both upper and lower stages on the energy ladder as income rises or depending on their preferences or needs (Arnold et al., 2006; Davis, 1998; Kowsari and Zerriffi, 2011; Lee et al., 2015; Martins, 2005).

Understanding the energy choices of low-income households is important in designing suitable policies to support the transition process and targeted measures to eliminate energy poverty. The presence of energy ladder or stacking transition patterns could lead to different sets of conclusions and policy recommendations. Moreover, the few empirical studies on household energy choice and transition in South Africa do not use panel data (Davis, 1998; Madubansi and Shackleton, 2006; Uhunamure et al., 2017), which among other things, enables the control of unobserved effects and explains energy choice over time.

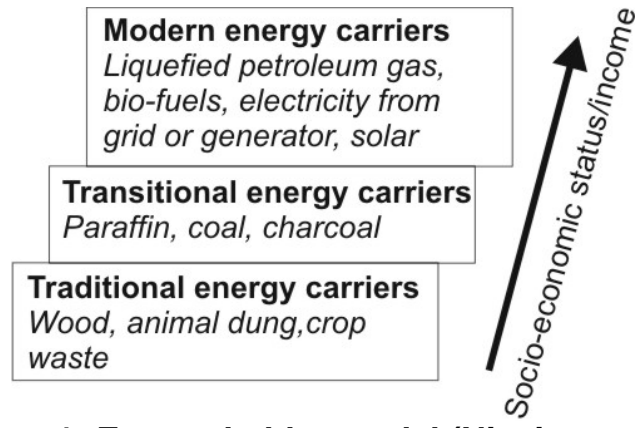

Figure 1: Energy ladder model (Nissing and Blottnitz, 2010; Van der Kroon et al., 2013).

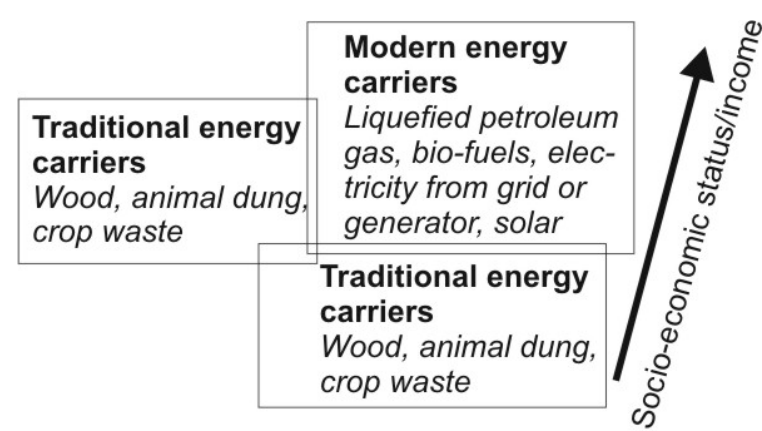

Figure 2: Energy stacking model (IEA, 2002; Van der Kroon et al., 2013).

This study aims to investigate whether the energy transition patterns by low-income households in South Africa follow the energy ladder or energy stacking models for cooking, heating and lighting energy services. If income is the major determinant of the transition to more modern energy sources, then specific energy policy may not be needed beyond providing access. The energy transition patterns in low-income households will therefore determine whether the development of an energy policy is necessary, bearing in mind that the main goal is sustainable energy use and energy poverty alleviation. Section 2 presents the data and methods while, Section 3 provides the results and discussion, and Section 4 presents conclusions.

\section{Data and methods 2.1 Data description}

The data employed for the analysis comes from the four waves of the National Income Dynamics Survey (NIDS). The survey began in 2008 (the baseline wave), with a nationally representative sample of 28 000 individuals in 7300 households across the country. The survey is repeated every two years with the same group of households or individuals, using 
a combination of household, adult, child and proxy questionnaires (Brown et al., 2012; Leibbrandt et al., 2009; NIDS, 2012).

\subsection{Model specification}

An ordered logit model, also known as the proportional odds model, is a statistical technique that takes ordering into account and the odds ratio of the event is independent of the category $j$ (Greene, 2008). An ordinal logit regression considers the probability of the event and all others above it in the ordinal ranking. In other words, an ordinal logit regression is concerned with cumulative probabilities rather than probabilities for discrete categories (Agresti, 2010).

Households face choices between traditional, transitional and modern energy carriers for cooking, heating and lighting and are assumed to maximise their utility by choosing one of the energy carriers as their main energy source for the specific end-use. Following the approach of O'Connell (2005), suppose data $\left(Y_{\mathrm{i}}, X_{1 \mathrm{i}} \ldots X_{\mathrm{ki}}\right)$ for observations $i=1, \ldots$. , $n$, where $Y$ is a response variable with $C$ ordered categories: $j=1, \ldots, C$, with probabilities, $P(Y=$ $j)=\pi^{(i)}$ and $X_{1} \ldots X_{\mathrm{k}}$ are $k$ explanatory variables and observations $Y_{i}$ are statistically independent of each other. Consider the $\mathrm{C}-1$ cumulative probabilities in Equations $1-3$.

$$
\begin{aligned}
& \gamma^{(j)}=P(Y \leq j)=\pi^{1}+\ldots+\pi^{(j)} \text { for } j \\
& =1, \ldots, C-1 \\
& \gamma^{(j)}=P(Y \leq j)=\pi^{2}+\ldots+\pi^{(j)} \text { for } j \\
& =2, \ldots, C-1 \\
& \gamma^{(j)}=P(Y \leq j)=\pi^{3}+\ldots+\pi^{(j)} \text { for } j \\
& =3, \ldots, C-1
\end{aligned}
$$

The following holds for $Y_{\mathrm{i}}^{(\mathrm{i})}=P\left(Y_{i} \leq j\right)$ for each unit $i$ and each category $j=1, \ldots, C$ - 1 , giving Equation 4.

$$
\begin{aligned}
& \log \left[Y_{i}^{(j)} / 1-Y_{i}^{(j)}\right]=\log \left[P\left(Y_{i} \leq j\right) / P\left(Y_{i}>j\right]\right. \\
& =\alpha^{j}-\left(\beta_{1} X_{1 i}+\ldots+\beta_{k} X_{k i}\right)
\end{aligned}
$$

Assume that the observed ordinal variable $Y_{i}$ is related to the latent variable according to Equation 5.

$$
Y_{i}=k \text { if } \mu_{k-1} \leq Y_{i}^{*} \leq \mu_{k} \text { for } k=1, \ldots . K
$$

The model for the cumulative probabilities is therefore given by Equation 6 .

$$
Y^{(\mathrm{j})}=\mathrm{P}(\mathrm{Y} \leq \mathrm{j})=\frac{\exp [\alpha j-(\beta 1 X 1 i+\ldots+\beta k X k i)]}{1+\exp [\alpha j-(\beta 1 X 1 i+\ldots+\beta k X k i)]}
$$

The intercept terms must be $\alpha^{(1)}<\alpha^{(2)}<\ldots<\alpha^{(\mathrm{C}-1)}$, to guarantee that $Y^{(1)}<Y^{(2)}<\ldots<\gamma^{(\mathrm{c}-1)}$. The parameters $\alpha$, called thresholds are in increasing or$\operatorname{der}\left(\alpha^{(1)}<\alpha^{(2)}<\ldots<\alpha^{(\mathrm{C}-1)}\right), \beta_{1}, \ldots, \beta_{k}$ are the same for each value of $j$. This is good for the parsimony of the model because it means that the effect of an explanatory variable on the ordinal response is described by one parameter (Agresti, 2010).

In the case of three ordered categories, Equation 6 simplifies to Equations 7-9.

$$
\begin{aligned}
& P(Y=1)=\frac{1}{1+\exp (\beta 1 \times 1 i-k 1)} \\
& P(Y=2)=\frac{1}{1+\exp (\beta 1 X 1 i-k 2)}-\frac{1}{1+\exp (\beta 1 \times 1 i-k 1)} \\
& P(Y=3)=1-\frac{1}{1+\exp (\beta 1 \times 1 i-k 2)}
\end{aligned}
$$

By maximum likelihood, estimates for $\alpha$ and $\beta$ can be obtained. The likelihood function for each $\mathrm{i}^{\text {th }} \mathrm{ob}$ servation can be expressed as Equation 10.

$$
\begin{aligned}
& \ell_{\mathrm{i}}(\alpha, \beta)=1\left[\mathrm{Y}_{\mathrm{i}}=0\right] \log \left[\Lambda\left(\alpha_{1}-\mathrm{X}_{1} \beta\right)\right] \\
& +\left[\mathrm{Y}_{\mathrm{i}}=1\right] \log \left[\Lambda\left(\alpha_{2}-\mathrm{X}_{1} \beta\right)-\Lambda\left(\alpha_{1}-\mathrm{X}_{1} \beta\right)\right] \\
& +\left[\mathrm{Y}_{\mathrm{i}}=1\right] \log \left[1-\Lambda\left(\alpha_{3}-\mathrm{X}_{1} \beta\right)\right]
\end{aligned}
$$

The parameters for an ordered logit model can be difficult to interpret, therefore, reporting marginal effects after an ordered logistic regression can make the results more understandable (Greene, 2008; Long and Freese, 2014). The marginal effects for the present study were calculated at the mean values in a covariate model showing how $\mathrm{P}(\mathrm{Y}=1)$ changes as the variables changes from 0 to 1 , holding all other variables at their means, i.e., the marginal effect approximates how much the dependent variable is expected to increase or decrease for a unit change in an explanatory variable so that the effect is presented on an additive scale (Buis, 2010). The marginal effects are derived by taking the partial derivatives of Equations 7, 8 and 9 and Equations 11, 12 and 13 are obtained.

$$
\begin{aligned}
& \partial \operatorname{Pr}(\mathrm{Y}=0 \mid \mathrm{X}) / \partial \mathrm{X}_{\mathrm{k}}=-\beta_{\mathrm{k}} \lambda\left(\alpha_{1}-\mathrm{X} \beta\right) ; \\
& \partial \operatorname{Pr}(\mathrm{Y}=\mathrm{j} / \mathrm{X}) / \partial \mathrm{X}_{\mathrm{k}}=\beta_{\mathrm{k}}\left[\lambda\left(\alpha_{\mathrm{j}-1}-\mathrm{X} \beta\right)\right. \\
& \left.-\lambda\left(\alpha_{3}-\mathrm{X} \beta\right)\right], \text { for } 0<\mathrm{j}<3 ; \text { and } \\
& \partial \operatorname{Pr}(\mathrm{Y}=3 / \mathrm{X}) / \partial \mathrm{X}_{\mathrm{k}}=\beta_{\mathrm{k}} \lambda\left(\alpha_{3}-\mathrm{X} \beta\right.
\end{aligned}
$$

The predicted probabilities are estimated as in Equations 14, 15 and 16.

$$
\begin{aligned}
& \mathrm{P}\left(\mathrm{Y} \_ \text {ordinal }=\text { 'less preferred' }\right) \\
& =\mathrm{P}(\mathrm{S}+\mathrm{u} \leq \text { _cut } 1) \\
& \mathrm{P}(\mathrm{Y} \text { _ordinal }=\text { 'moderately preferred' }) \\
& =\mathrm{P}\left({ }_{-} \text {cut } 1<\mathrm{S}+\mathrm{u} \leq \text { _cut } 2\right)
\end{aligned}
$$




$$
\begin{aligned}
& \mathrm{P}\left(\mathrm{Y}_{-} \text {ordinal }=\text { 'most preferred' }\right) \\
& =\mathrm{P}\left({ }_{-} \text {cut } 2<\mathrm{S}+\mathrm{u}\right)
\end{aligned}
$$

In which the basic equation is written according to Equation 17.

$$
\operatorname{Pr}(\mathrm{Y}=\mathrm{j} \mid \mathrm{X})=F\left(\widehat{T}_{j}-X_{1} \hat{\beta}\right)-F\left(\widehat{T}_{j-1}-X_{1} \hat{\beta}\right)
$$

Based on the assumptions of the 'energy ladder', modern energy carriers should be the source most preferred (being on top of the ladder) by the lowincome households for cooking, heating and lighting. Transitional energy carriers are assumed to be moderately preferred, being in the middle of the ladder, while traditional energy carriers will be less preferred because they are at the bottom of the ladder.

\subsection{Procedures and technique of analysis}

The description of low-income households for the allocation of FBE is households where the gross monthly income of all the members of the household does not exceed two old age pensions (DME, 2003). The dataset for low-income households from the NIDS study contained 10804 observations. A balanced panel data model was used for the analysis to track the energy transition of the low-income households. A panel is said to be balanced if it had the same time or periods, $t=1 \ldots \mathrm{T}$, for each crosssectional observation (Hsiao, 2014). A balanced panel dataset will contain all elements observed in all period allowing an observation of the same household across the years of survey. An average observation of 760 low-income households was used for the analysis.

The independent variables or the endogenous characteristics to be used were first tested for multicollinearity. (See the supplementary information for the description and measurement. ${ }^{1}$ ) The independent variables include income, age, gender, rurality, household size and dwelling type. The variable 'Year' is also included as part of the independent variables. The variance inflation factor (VIF) and tolerance value were used to detect whether multi-collinearity existed among the variables. A variable whose VIF value is greater than 10 or the tolerance value is lower than 0.1 means that there is a linear combination of other independent variables and thus may merit further investigation (Gujarati and Porter, 2009). The test result shows that the VIF for each independent variable is less than 1.5 and the tolerance value ranges from 0.7 to 0.9 . Multi-collinearity, is as such, not a threat for the regression analysis.

\section{Results and discussion}

The sample households used different types of energy carriers for their cooking, heating and lighting. Modern energy carriers include electricity from the grid, gas, solar energy and electricity from a generator. Transitional energy carriers comprise paraffin and coal, while traditional energy carriers include animal dung and wood. A definition of the different energy choices by South African low-income households for cooking (Panel 1), heating (Panel 2) and lighting (Panel 3) from 2008 to 2014 is given in terms of Figure 3.

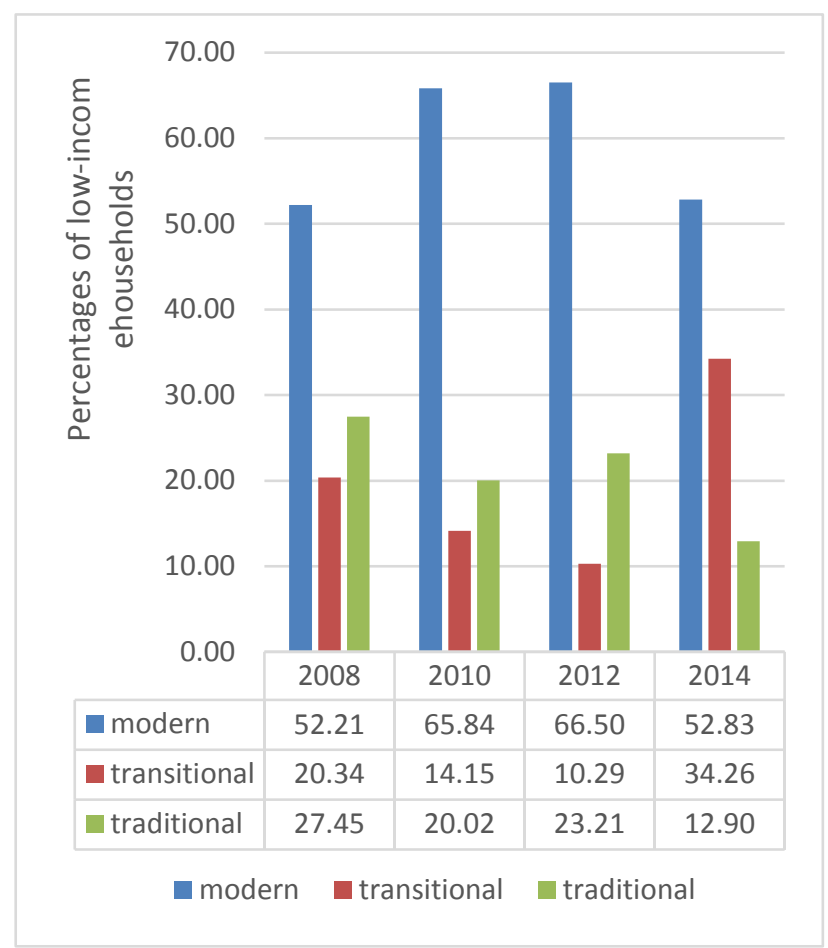

(a)

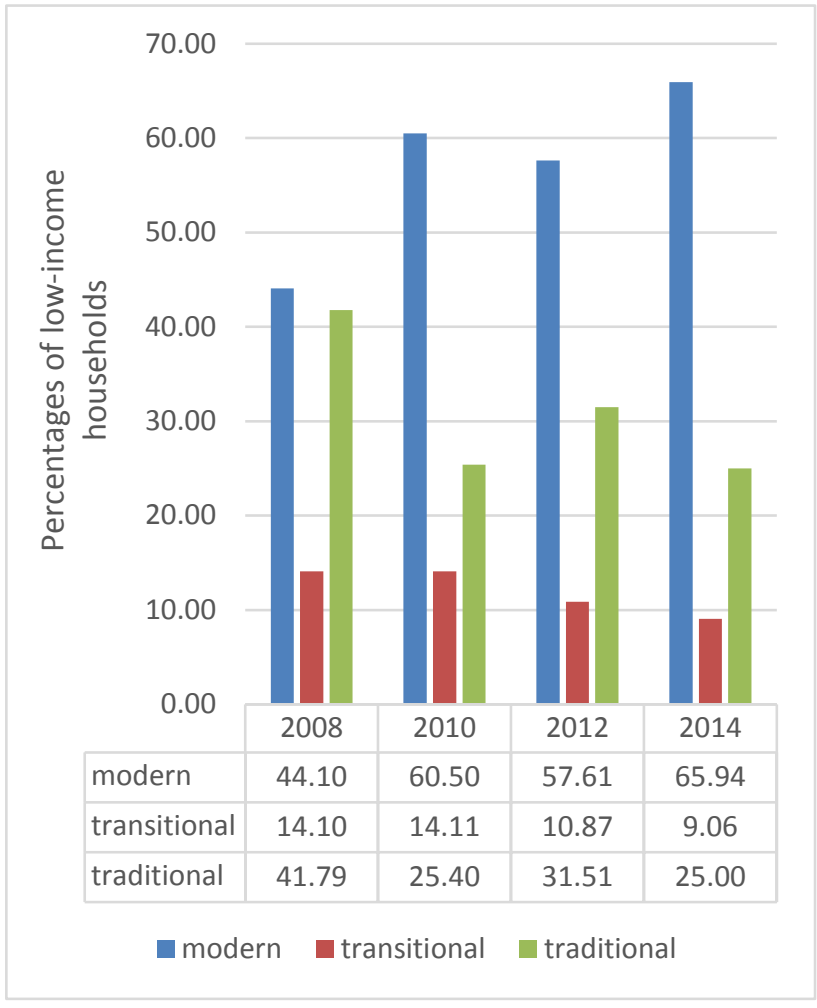

(b) 


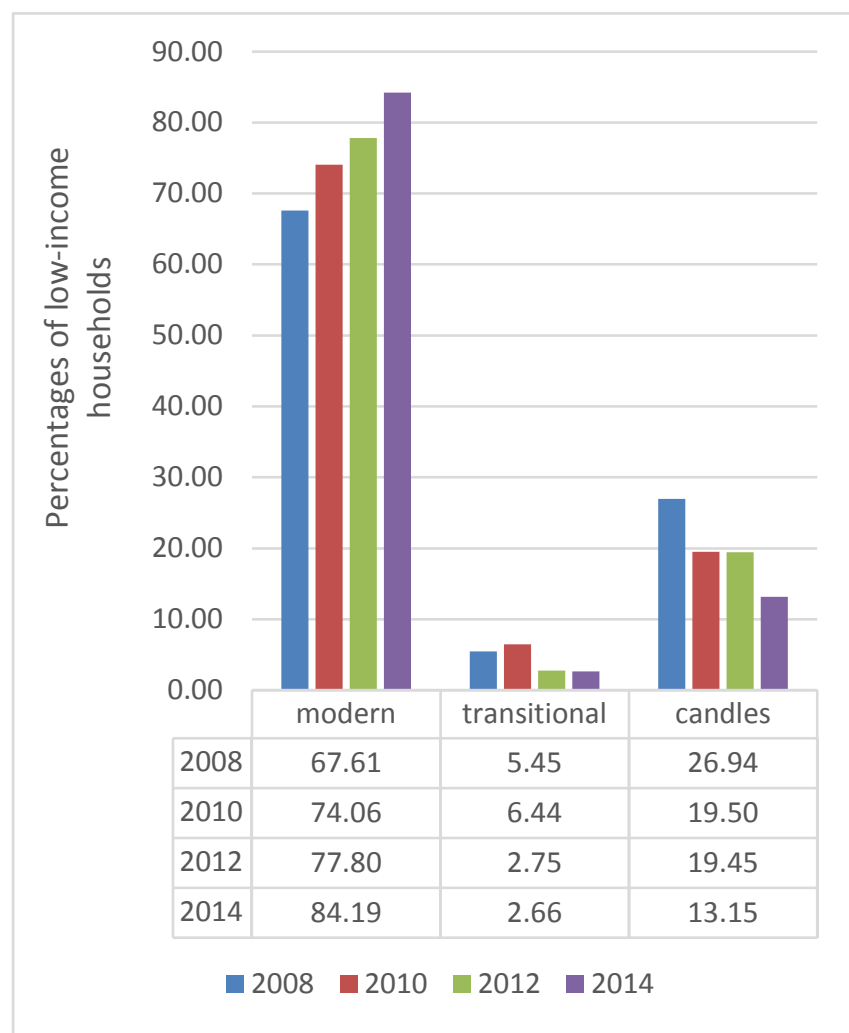

(c)

Figure 3: Energy choices for cooking heating and lighting, where (a), (b) and (c) = Panels 1, 2 and 3 of cooking, heating and lighting respectively.

The use of modern energy for cooking was predominant across the waves. Wave 3 , year 2012, had the highest percentage $(67 \%)$ of low-income households using modern energy carriers. There was, however, a sharp increase in the use of transitional energy carriers, from $10 \%$ in 2012 to $34 \%$ in 2014. This could mean that substitution of modern energy for transitional energy occurs because of an increase in the price of modern energy carriers, forcing a change in energy choice. Traditional energy carriers in 2014 were used in a small percentage of households $(13 \%)$ as the main energy source for cooking.

Modern energy carriers for space heating were the most common across the waves, with 2014 recording the highest proportion (66\%) for low-income households. In the same year, households used fewer of the transitional energy carriers for space heating, in $9 \%$ of cases, compared with other waves. These trends illustrate energy substitution strategies in which modern energy carriers become increasingly used for space heating. More households $(42 \%)$ used traditional energy carriers for space heating in 2008 than in other years but the use of modern energy carriers for space heating in the same year was relatively low (44\%). The use of transitional energy carriers for space heating appeared to be phased out.
The use of traditional energy carriers for lighting doesn't feature, and as such, no case of the households across the waves was observed. The use of modern energy carriers for lighting was predominant across the four waves and increasingly so: by 2014 the largest percentage (84\%) ever of households was using this source. The use of candles for lighting seems to be phased out as the number of households using candles for lighting declines. Transitional energy carriers for lighting were no longer often used by households.

\subsection{Marginal effects for energy choice for cooking}

The marginal effects after ordered logistic regression with respect to cooking are shown in Table 1 . These provide the amount of change in $Y$ that will be produced by a unit change in $X_{k}$ holding other independent variables constant at their reference points. The reference point for dwelling type is modern dwelling, gender - female, geographical location urban and household size - small (1-4 persons). Income and age are set at their means, which are respectively - ZAR 825.88 (per month) and 50.82 years. For the 'year' variable, Stata (a statistical software that enables users to analyse, manage, and produce graphical visualisations of data) sets a mean for 2010, 2012 and 2014.

All of the following independent variables are expected to have negative signs for traditional and transitional energy carriers holding other independent variables constant at the reference points. This will be the case for all situations considered. For gender, rurality, household size, and dwelling type, it is expected that the marginal effect will be that lowincome households with a female household respondent, in an urban settlement, having a small household size and living in a modern dwelling will make less use of traditional and transitional energy carriers for cooking and heating. For lighting, it is expected that the marginal effect will be that lowincome households with a female household respondent, in an urban settlement, having a small household size and living in a modern dwelling are expected to use few candles plus transitional energy carriers. The expected signs are presumed to be negative, knowing that health and safety risks are associated with traditional or transitional energy carriers and candles compared with modern energy carriers (Kowsari and Zerriffi, 2011; Swart and Bredenkamp, 2012).

Age is an ambiguous variable as it is unknown $a$ priori if it positively or negatively influenced household energy choice for cooking and heating. For household income, the a priori expectation with respect to the sign is also ambiguous, depending on which energy transition model holds (energy ladder or energy stacking). 
For the 'year' variables, it is expected that lowincome households in 2010, 2012, and 2014 will use less traditional or transitional energy carriers than they did in the base year 2008 for their cooking and heating. For lighting, it is expected that low-income households in 2010, 2012, and 2014 will use fewer candles.

Furthermore, the a priori expectations of each independent variable for a modern energy carrier is different from those for traditional and transitional energy carriers. Thus, for gender, rurality, household size, and dwelling type, a positive sign is expected. Therefore, the marginal effect is expected to be that low-income households with a female household respondent, in an urban settlement, having a small household size, and in a modern dwelling are more likely to use modern energy carriers for their cooking, heating, and lighting. Positive signs are expected for modern energy carrier usage because it impacts on human well-being by reducing the health and safety risks associated with traditional or transitional energy carriers (Kowsari and Zerriffi, 2011; Swart and Bredenkamp, 2012). The use of modern energy carriers could decrease time budget constraints on household members particularly women and children, increase labour productivity, and improve gender inequality and literacy (Howells et al, 2003; Swart and Bredenkamp, 2012).

Household income and age may be either positive or negative, as with the a priori expectations for traditional and transitional energy carriers.

Finally, for the 'year' variable, low-income households in 2010, 2012, and 2014 are hypothesised to have positive signs for modern energy carriers. The marginal effect is expected to be that lowincome households are more likely to use modern energy carriers for cooking, heating, and lighting in 2010, 2012, and 2014 than was the case in the base year 2008 .
In the interpretation of the results, household income is an important variable, as it determines the energy consumption for low-income households. Therefore, if low-income households move up the energy ladder as their income increase, the 'energy ladder' model is confirmed. This is assessed if income is statistically significant in relation to a household's decision concerning the energy choices for cooking, heating and lighting, holding other variables constant. From a policy point of view, if income were the major determinant of a complete transition to modern energy sources, the implication is that energy transition will take place automatically as household income increases, thus reducing energy poverty. Beyond providing access, specific energy policy may not be needed.

The 'energy stacking' model, on the other hand, hypothesises that households continue to use a mixture of energy sources, even if their income increases. Therefore, if income is not statistically significant in relation to the household's decision concerning energy choices for cooking, heating, and lighting, this may provide support for the 'energy stacking' model. In this case, one cannot assume that an increase in household income will automatically result in a transition to cleaner and more efficient modern carriers, in which case more specific energy policies may be needed. The marginal effects with respect to cooking energy service are presented in Table 1.

Real income is statistically significant for both traditional and modern energy carriers at the $10 \%$ level of significance. This result has partly confirmed an 'energy ladder' behaviour with respect to cooking. The implication is that as real income rises, there is transition up the energy ladder for the choice of energy source for cooking. Therefore, households initially using a traditional energy source for cooking

Table 1: Marginal effects for energy choice for cooking.

\begin{tabular}{lccc}
\hline & $\begin{array}{c}\text { Marginal effects for trad- } \\
\text { itional energy carrier }\end{array}$ & $\begin{array}{c}\text { Marginal effects for } \\
\text { transitional energy carrier }\end{array}$ & $\begin{array}{c}\text { Marginal effects for } \\
\text { modern energy carrier }\end{array}$ \\
\hline Real income & $-5.44 e-05^{*}$ & $-2.97 e-05$ & $8.42 e-05^{*}$ \\
Dwelling type (modern) & $-0.1807^{* * * *}$ & $-0.0735^{* * * *}$ & $0.2542^{* * *}$ \\
Age & $8.09 e-05$ & $4.42 e-04$ & -0.0012 \\
Gender (female) & -0.0107 & -0.0057 & 0.0164 \\
Rurality (urban) & $-0.2043^{* * * *}$ & $-0.1055^{* * * *}$ & $0.3099^{* * * *}$ \\
Household size (small) & $-0.1086^{* * *}$ & $-0.0440^{* * *}$ & $0.1526^{* * *}$ \\
Year (2010) & $-0.0685^{* * *}$ & $-0.0413^{* * *}$ & $0.1101^{* * *}$ \\
Year (2012) & $-0.0959^{* * * *}$ & $-0.0599^{* * * *}$ & $0.1559^{* * * *}$ \\
Year (2014) & $-0.0947^{* * *}$ & $-0.0598^{* * *}$ & $0.1546^{* * *}$ \\
\hline
\end{tabular}

T-statistics in parentheses: * significant at $10 \%$; ** significant at $5 \%$; *** significant at $1 \%$ 
will switch automatically to a transitional or a modern energy carrier as their income rises.

Dwelling type (modern), rurality (urban) and household size (small) have negative signs and are statistically significant at 1,1 and 5 percent level of significance respectively for traditional and transitional energy carriers. For dwelling type, for example, low-income households living in modern dwellings are $10 \%$ less likely to use traditional energy carriers and $8 \%$ less likely to use transitional energy carriers for cooking than their counterparts living in non-modern dwellings. For a modern energy carrier, the sign for modern dwelling type is positive; therefore, low-income households living in modern dwellings are $19 \%$ more likely to use a modern energy carrier than low-income households living in traditional or informal dwellings for their cooking. Thus, the expectation that a modern dwelling enhances the probability of choosing a modern energy carrier for cooking was substantiated, even when income was held constant.

For rurality, urban low-income households are $15 \%$ less likely to use traditional energy carriers and $11 \%$ less likely to use transitional energy carriers for cooking than rural low-income households. For the modern energy carrier, the sign for urban is positive. In consequence, urban low-income households are $27 \%$ more likely to adopt a modern energy carrier for cooking compared with rural low-income households.

For household size, small low-income households are $5 \%$ less likely to use a traditional energy carrier for cooking than their larger counterparts. Small low-income households are 5\% less likely to use a transitional energy carrier for cooking than larger low-income households. For modern energy carriers, the sign for small household size is positive. It implies that small low-income households are $10 \%$ more likely to use modern energy carriers for cooking than their larger counterparts, even holding income and location constant.

The 'year' variables, 2010, 2012 and 2014 have negative signs for traditional and transitional energy carriers. The implication is that in 2010, 2012 and 2014, low-income households were respectively $3 \%, 4 \%$ and $4 \%$ less likely to use traditional energy carriers for cooking than in 2008. Low-income households were $3 \%$ less likely to use transitional energy carriers for cooking in 2010, $4 \%$ less likely in 2012 and 2014 than in 2008. For the modern energy carrier, however the signs for 2010, 2012 and 2014 were positive. This implies that low-income households were $6 \%$ more likely to use modern energy carriers for cooking in 2010 than in 2008 and 8\% more likely in 2012 and 2014 than in 2008. South Africa, therefore recorded progress in terms of improving the use of modern energy sources.
The study further analysed the predicted probabilities of the low-income households for the choice of energy for cooking to see their probability of preference and to determine if the result of the logistic regression makes sense. The predicted probabilities for energy choice for cooking are presented in Table 2 .

\section{Table 2: Predicted probabilities for energy choice for cooking}

95\% confidence interval

$\operatorname{Pr}(\mathrm{y}=1=$ less preferred

[0.1531, 0.2120]

$\mathrm{x}: 0.1826$

$\operatorname{Pr}(y=2=$ moderately pre-

[0.1504, 0.2102]

ferred | x: 0.1803

$\operatorname{Pr}(\mathrm{y}=3=$ most preferred

$[0.5987,0.6755]$

$\mathrm{x}: 0.6371$

The interpretation of the result was that there was a $64 \%$ probability of the choice of modern energy carriers being most preferred for cooking by low-income households, holding other variables constant at their reference points. There was also $18 \%$ probability that low-income households would choose transitional energy carriers, which was a moderately preferred energy choice for their cooking, holding other variables in the model constant at their reference points. There was, lastly, $18 \%$ probability that the low-income households would choose the option of traditional energy carriers for cooking, which was a less preferred option, holding other variables in the model constant at their reference points. This conforms to expectations.

\subsection{Marginal effects for energy choice for heating}

Table 3 presents the marginal effects after ordered logistic regression with respect to heating energy service.

Real income was not a statistically significant determinant of household energy choice for heating, therefore even if household income rose, the switch to modern energy sources would not be automatic, as explained by the energy ladder theory. Other variables such as being in a modern dwelling type, located in an urban area and having a smaller household size all increased the probability of using a modern energy source for heating, and were statistically significant at the 1, 1 and 5 percent level of significance respectively.

For dwelling type, low-income households living in modern dwellings were $18 \%$ less likely to use a traditional energy carrier, $8 \%$ less likely to use transitional energy carrier for heating, and $27 \%$ more 
Table 3: Marginal effects for energy choice for heating.

\begin{tabular}{lccc}
\hline & $\begin{array}{c}\text { Marginal effects for trad- } \\
\text { itional energy carrier }\end{array}$ & $\begin{array}{c}\text { Marginal effects for trans- } \\
\text { itional energy carrier }\end{array}$ & $\begin{array}{c}\text { Marginal effects for } \\
\text { modern energy carrier }\end{array}$ \\
\hline Real income & $-2.98 e-05$ & $-2.33 e-05$ & $5.32 e-05$ \\
Dwelling type (modern) & $-0.1846^{* * * *}$ & $-0.0876^{* * * *}$ & $0.2723^{* * * *}$ \\
Age & 0.0007 & 0.0005 & -0.0013 \\
Gender (female) & 0.0086 & 0.0069 & -0.0156 \\
Rurality (urban) & $-0.2047^{* * *}$ & $-0.0916^{* * * *}$ & $0.2964^{* * * *}$ \\
Household size (small) & $-0.0711^{* *}$ & $-0.0462^{* * *}$ & $0.1173^{* *}$ \\
Year (2010) & $-0.0794^{* * *}$ & $-0.0664^{* * *}$ & $0.1458^{* * *}$ \\
Year (2012) & $-0.0621^{* * *}$ & $-0.0517^{* * *}$ & $0.1138^{* * *}$ \\
Year (2014) & $-0.0635^{* * *}$ & $-0.0531^{* * *}$ & $0.1167^{* * *}$ \\
\hline
\end{tabular}

T-statistics in parentheses: * significant at 10\%; ** significant at $5 \%$; *** significant at $1 \%$

likely to use a modern energy carrier for space heating.

Similarly, urban low-income households were $21 \%$ less likely to use traditional energy carriers for heating, $9 \%$ less likely to use transitional energy carriers and $30 \%$ more likely to use modern energy carriers.

Low-income small households were $7 \%$ less likely to use traditional energy carriers, $5 \%$ less likely to use transitional energy carriers and $18 \%$ more likely to use modern energy carriers for heating. Therefore, with household size, as found with the energy choice for cooking, small household size implied less energy demand and therefore the low-income households would prefer to use a modern energy carrier for space heating.

The inference for the 'year' variables is that lowincome households were $8 \%$ less likely to use traditional energy carriers in 2010 than in 2008 and 6\% less likely in 2012 and 2014 than in 2008. For modern energy carriers, low-income households were $15 \%$ more likely to use them for heating in 2010 , $11 \%$ more likely in 2012 and $12 \%$ more likely in 2014 than 2008.

As found with the choice of energy for cooking, the variables, age and gender of the household head were not statistically significant, indicating they were not relevant in influencing the choice of energy carriers (traditional, transitional or modern) for heating by low-income households, holding all other variables in the model constant.

The predicted probabilities for the energy choice for heating by low-income households are given in Table 4. In Table 4, the outcome showed a 54\% probability that a modern energy carrier would be chosen for heating among low-income households considerably less than for cooking. There was a $19 \%$ probability that a transitional energy carrier would be chosen and $28 \%$ probability for the option of a traditional energy carrier for space heating, holding other variables constant at their means.

Table 4: Predicted probabilities for energy choice for heating.

\begin{tabular}{lc}
\hline & $\begin{array}{c}95 \% \text { confidence } \\
\text { interval }\end{array}$ \\
\hline $\begin{array}{l}\operatorname{Pr}(y=1=\text { less preferred } \\
\mid \mathrm{x}: 0.2755\end{array}$ & {$[0.2380,0.3129]$} \\
$\begin{array}{l}\operatorname{Pr}(y=2=\text { moderately } \\
\operatorname{preferred} \mid \mathrm{x}: 0.1886\end{array}$ & {$[0.1549,0.2223]$} \\
$\operatorname{Pr}(y=3=$ most preferred & {$[0.4934,0.5784]$} \\
$\mid \mathrm{x}: 0.5359$ & \\
\hline
\end{tabular}

\subsection{The result of marginal effects for energy choice for lighting}

Table 5 presents the marginal effects for lighting energy service to be compared with those in Tables 1 and 3.

Energy choice for lighting was also not statistically affected by income. While heating is very energy intensive (and thus expensive), lighting is very energy efficient and thus affordable for almost all low-income households. Figure 3 shows that a clear majority of low-income households (84\% in 2014) used a modern energy source for lighting. Dwelling type (modern) and rurality (urban) were, however, statistically significant determinants of energy choice at the $1 \%$ level of significance and had negative signs for traditional and transitional energy carriers.

Low-income households living in modern dwellings were $17 \%$ less likely to use candles, $3 \%$ less likely to use transitional energy carriers and $21 \%$ more likely to use modern energy carriers for lighting than those living in non-modern dwellings.

Similarly, urban low-income households were $6 \%$ less likely to use candles for lighting, $1 \%$ less 
Table 5: Marginal effects for energy choice for lighting.

\begin{tabular}{lccc}
\hline & $\begin{array}{c}\text { Marginal effects for } \\
\text { candles }\end{array}$ & $\begin{array}{c}\text { Marginal effects for trans- } \\
\text { itional energy carrier }\end{array}$ & $\begin{array}{c}\text { Marginal effects for } \\
\text { modern energy carrier }\end{array}$ \\
\hline Income & $-2.67 e-05$ & $-6.69 e-06$ & $3.34 e-05$ \\
Dwelling type (modern) & $-0.1792^{* * * *}$ & $-0.0327^{* * * *}$ & $0.2120^{* * * *}$ \\
Age & 0.0001 & $2.76 e-05$ & -0.0001 \\
Gender (female) & -0.0311 & -0.0074 & 0.0385 \\
Rurality (urban) & $-0.0576^{* * * *}$ & $-0.0131^{* * * *}$ & $0.0708^{* * * *}$ \\
Household size (small) & -0.0176 & -0.0042 & 0.0219 \\
Year (2010) & -0.0155 & -0.0039 & 0.0195 \\
Year (2012) & -0.0303 & -0.0077 & 0.0380 \\
Year (2014) & $-0.0498^{* * *}$ & $-0.0129^{* * *}$ & $0.0627^{* * * *}$ \\
\hline
\end{tabular}

T-statistics in parentheses: * significant at 10\%; ** significant at $5 \%$; ** significant at $1 \%$

likely to use transitional energy carriers and $7 \%$ more likely to use modern energy carriers than rural low-income households, holding other variables in the model constant. This marginal effect implied that there was much less difference in the probability of using modern energy carriers for lighting between urban/rural than there was for cooking and heating.

Table 5 shows that 2014 was statistically significant at the $1 \%$ level of significance for candles and the $5 \%$ level of significance for transitional energy carriers and had negative signs. Thus, in 2014, lowincome households were $5 \%$ less likely to use candles compared with 2008 and $1 \%$ less likely to use transitional energy carriers compared with 2008. For the modern energy carrier, the marginal effect suggests that the low-income households are $6 \%$ more likely to use modern energy carrier for lighting than in 2008 , holding other variables in the model constant at their means. Unexpectedly, 2010 and 2012 were not statistically significant for the three energy choice options as they were for cooking and heating. This may be caused by electricity supply crises faced by the country with emergencies in supply declared in 2008/2009.

Finally, in addition to the 'year' variables, age and gender of the household head and the size of the household were statistically insignificant, indicating they were not relevant in influencing the choice of energy carriers for lighting by low-income households.

The predicted probabilities for energy choice for lighting by low-income households is thus shown in Table 6. Notably, in making the energy choice for lighting, 'less preferred' is associated with candles, 'moderately preferred' with transitional energy carriers and 'most preferred' with modern energy carriers. The result from Table 6 implied that there was a $77 \%$ probability that a modern energy carrier would be chosen for lighting and less than $1 \%$ probability that the low-income households were likely to opt for transitional energy carriers. Lastly, there was $19 \%$ probability that low-income households would choose candles for lighting. For cooking, the predicted probability was $60 \%$; it was $54 \%$ for heating and $77 \%$ for lighting. These percentages reflect the energy intensity needed for each service considering electricity as the source of energy.

Table 6: Predicted probabilities for energy choice for lighting.

\begin{tabular}{lc}
\hline & $\begin{array}{c}95 \% \text { confidence } \\
\text { interval }\end{array}$ \\
\hline $\operatorname{Pr}(y=1=$ less preferred | & {$[0.0316,0.0629]$} \\
x: 0.1871 & \\
$\operatorname{Pr}(y=2=$ moderately pre- & {$[0.1572,0.2168]$} \\
ferred $\mid x: 0.047$ & \\
$\operatorname{Pr}(y=3=$ most preferred | & {$[0.7329,0.7986]$} \\
x: 0.7657 & \\
\hline
\end{tabular}

\section{Conclusions}

The quantitative insight on energy ladder behaviour for cooking is one key finding in this study; low-income households that originally used traditional or transitional energy carriers would shift up to transitional or modern energy carriers for cooking as their income increases. The importance of low-income households adopting energy ladder behaviour is the reduction in the use of traditional or transitional energy carriers; this in turn has positive external results for society, including less deforestation and reduced greenhouse gas emissions into the atmosphere (Baiyegunhi and Hassan 2014).

The implication of the finding regarding energy stacking is that even in South Africa, where most people have access to electricity; some households 
still demonstrate energy poverty. The use of energy efficient appliances for heating could assist in the switch to modern energy carriers. Policies to reduce energy poverty need a multi-pronged approach, not only a focus on electricity access. Rural low-income households have greater access to wood than urban ones, and could be using fuelwood as energy security or for some cultural preferences (especially when it comes to cooking).

The type of dwelling and geographical location could aid the adoption of modern energy carriers by low-income households. Suitable measures to combat energy poverty should therefore be urban-rural specific. This information is important for providing support for the design and implementation of effective energy policies for the residential sector.

\section{Note}

1. A supplementary file containing the variable description and measurement, literature on energy transition patterns and determinants of energy choice by lowincome households in developing countries is available at:

https://journals.assaf.org.za/jesa/article/view/4389.

\section{References}

Agresti, A. 2010. Analysis of ordinal categorical data, Second edition. New York: Wiley. https://doi.org/10.1002/9780470594001

Arnold, J.E.M., Kohlin, G. and Persson, R. 2006. Wood fuels, livelihoods and policy interventions: Changing perspectives. World Development, 34 (3): 596-611. https://doi.org/10.1016/j.worlddev.2005.08.008

Baiyegunhi, L.J.S. and Hassan, M.B. 2014. Rural household fuel and energy transition: Evidence from Giwa LGA Kaduna State, Nigeria. Energy for Sustainable Development, 20: 30-35.

Brown, M., Daniels, R., De Villiers, L., Leibbrandt, M. and Woolard, I. 2012. National Income Dynamics Study Wave 2 User Manual. Southern Africa Labour and Development Research Unit, University of Cape Town, Cape Town, South Africa.

Buis, M. 2010. Interpretation of interactions in non-linear models. The Stata Journal, 10: 305-308.

Davis, M. 1998. Rural household energy consumption: The effects of access to electricity- Evidence from South Africa. Energy Policy, 26(3): 207-217. https://doi.org/10.1016/S0301-4215(97)00100-6

Department of Energy (DoE). 2013. Integrated Resource Plan for Electricity (IRP) 2010-2030. Update report 2013. Pretoria: South Africa.

Department of Minerals and Energy (DME). 2003. Electricity basic services support tariff (free basic electricity policy). Pretoria. Available at: www.energy.gov.za

Greene, W.H. 2008. Econometric analysis. Sixth Edition. Upper Saddle River, New Jersey: Prentice Hall.

Gujarati, D.N. and Porter, D.C. 2009. Basic econometrics. Fifth Edition. Mc Graw-Hill, New York.
Hosier, R.H. and Dowd, J. 1987. Household fuel choice in Zimbabwe: An empirical test of the energy ladder hypothesis. Journal of Resources and Energy, 9: 347-361. https://doi.org/10.1016/0165-0572(87)90003-X

Howells, M.I., Alfstad, T., Victor, D.G., Goldstein, G. and Remme, U. 2003. An energy model for a low income rural African village. Energy Research Centre, University of Cape Town, Cape Town, South Africa. Working Paper Number 18.

Hsiao, C. 2014. Analysis of panel data, Volume 54. Cambridge University Press. https://doi.org/10.1017/CBO9781139839327

Inglesi-Lotz, R. 2010. Electricity demand in South Africa: Conditional forecasts to 2030. Applied Energy, 87: 197-204. https://doi.org/10.1016/j.apenergy.2009.08.017

International Energy Agency (IEA). 2002. Energy poverty. World Energy Outlook. Paris.

Joyeux, R. and Ripple, R.D. 2007. Household energy consumption versus income and relative standard of living: A panel approach. Energy Policy, 35 (1): 50 60. https://doi.org/10.1016/j.enpol.2005.10.012

Kowsari, R. and Zerriffi, H. 2011. Three dimensional energy profiles: A conceptual framework for assessing household energy use. Journal of Energy Policy, 39: 7505-7517. https://doi.org/10.1016/j.enpol.2011.06.030

Lay, J., Ondraczek, J. and Stoever, J. 2013. Renewables in the energy transition: Evidence on solar home systems and lighting fuel choice in Kenya. Energy Economics, 40: 350-359. https://doi.org/10.1016/j.eneco.2013.07.024

Lee, S.M., Kim, Y., Jaung, W. Latifah, S., Afifi, M. and Fisher, L.A. 2015. Forests, fuelwood and livelihoods - Energy transition patterns in Eastern Indonesia. Energy Policy, 85: 61-70. https://doi.org/10.1016/j.enpol.2015.04.030

Leibbrandt, M., Woolard, I. and de Villiers, L. 2009. Methodology: Report on NIDS Wave 1. Southern Africa Labour and Development Research Unit (SALDRU), University of Cape Town, Cape Town, South Africa. Technical paper, volume 1.

Liu, W., Spaargaren, G., Heerick, N., Mol, A.P.J. and Wang, C. 2013. Energy consumption practices of rural households in North China: Basic characteristics and potential for low carbon development. Energy Policy, 55: 128-138. https://doi.org/10.1016/j.enpol.2012.11.031

Long, J.S. and Freese, J. 2014. Regression models for categorical dependent variables using Stata. Third Edition. College Station, Texas, USA: Stata.

Madubansi, M. and Shackleton, C.M. 2006. Changing energy profiles and consumption patterns following electrification in five rural villages, South Africa. Energy Policy, 34(18): 4081-4092. https://doi.org/10.1016/j.enpol.2005.10.011

Martins, J. 2005. The impact of the use of energy sources on the quality of life of poor communities. Social Indicators Research, 72: 373-402. https://doi.org/10.1007/s11205-004-5583-z 
National Income Dynamics Study (NIDS) 2012. Wave 1: Introduction to NIDS data, Cape Town: Southern Africa Labour and Development Research Unit (SALDRU), University of Cape Town, Cape Town, South Africa.

Nissing, C. and von Blottnitz, H. 2010. Renewable energy for sustainable urban development: Redefining the concept of energisation. Energy Policy, 38: 21792187.

https://doi.org/10.1016/i.enpol.2009.12.004

O'Connell, A. A. 2005. Logistic regression models for ordinal response variables. Thousand Oaks, California, USA: Sage.

Ruiters, G. 2009. Free Basic Electricity in South Africa: A strategy for helping or containing the Poor? In: McDonald, D.A. (Ed.), Electric capitalism: Recolonising Africa on the power grid. Cape Town: HSRC.

Suliman, K.M. 2013. Factors affecting the choice of households' cooking fuel in Sudan. Working paper.

Swart, D. and Bredenkamp, B. 2012. The challenge of addressing household energy poverty. Conference paper presented at 'Towards Carnegie' in University of Cape Town, Cape Town, South Africa. September 3-7.

Uhunamure, S.E., Nethengwe, N.S. and Musyoki, A. 2017. Driving forces for fuelwood use in households in the Thulamela municipality, South Africa. Journal of Energy in Southern Africa, 28(1): 25-34. https://doi.org/10.17159/24133051/2017/v28i1a1635

Van der Kroon, B., Brouwer, R. and van Bekeuring, P.J.H. 2013. The energy ladder: Theoretical myth or empirical truth? Results from a meta-analysis. Renewable and Sustainable Energy Reviews, 20: 504-513. https://doi.org/10.1016/j.rser.2012.11.045 